\title{
Pulmonary hypertension is associated with worse early and late outcomes after aortic valve replacement: Implications for transcatheter aortic valve replacement
}

\author{
Eric E. Roselli, MD, ${ }^{a}$ Anas Abdel Azim, MD, MSc, ${ }^{a}$ Penny L. Houghtaling, MS, ${ }^{b}$ Wael A. Jaber, MD,${ }^{c}$ and
} Eugene H. Blackstone, $\mathrm{MD}^{\mathrm{a}, \mathrm{b}}$

\begin{abstract}
Objectives: Our objectives were to determine the prevalence of pulmonary hypertension (PHT) in patients undergoing aortic valve replacement (AVR) for severe aortic stenosis (AS), characterize risk for PHT, assess changes in PHT, and analyze its effect on outcomes.
\end{abstract}

\begin{abstract}
Methods: From January 1996 to July 2010, a total of 4372 patients with severe AS underwent primary AVR. Right ventricular systolic pressure (RVSP), a surrogate for PHT, was estimated echocardiographically in 2385, the study group. Preoperative RVSP was less than $35 \mathrm{~mm} \mathrm{Hg}$ (low pressure) in 611, 35 to $50 \mathrm{~mm} \mathrm{Hg}$ (moderate PHT) in 1199, and greater than $50 \mathrm{~mm} \mathrm{Hg}$ (high PHT) in 575. From active follow-up, 10,218 patient-years were available for survival analysis and 3716 echocardiograms after AVR for assessing RVSP.
\end{abstract}

\begin{abstract}
Results: Median preoperative RVSP was $41 \mathrm{~mm} \mathrm{Hg}$ (range, 10-104 mm Hg). Older, more symptomatic female patients with more comorbidities and tricuspid or mitral regurgitation had higher RVSP. Hospital mortality was higher in those with higher RVSP $(0.9 \%$ low presssure, $1.9 \%$ moderate PHT, $3.1 \%$ high PHT, $P=.03)$, as was risk of renal $(P<.0001)$ or respiratory failure $(P<.0001)$, sepsis $(P=.01)$, and prolonged hospitalization $(P<.0001)$. Initial post-AVR RVSP improvement was not maintained but rose to preoperative levels by 3 to 4 years. Long-term survival was worse in patients with higher RVSP $(P<.0001): 85 \%$ and $63 \%$ low pressure; $77 \%$ and $45 \%$ moderate PHT; and $62 \%$ and $31 \%$ high PHT at 5 and 10 years, respectively.
\end{abstract}

Conclusions: Most patients undergoing primary AVR have at least moderate PHT that is not relieved by AVR; its severity is associated with mortality, serious complications, and worse late survival. PHT severity should be included in risk assessment before aortic valve intervention. These outcomes suggest that earlier intervention for AS warrants further study. (J Thorac Cardiovasc Surg 2012;144:1067-74)

Supplemental material is available online.

Pulmonary hypertension (PHT) is common in patients with severe aortic stenosis (AS). ${ }^{1-4}$ Its presence has been suggested to reflect late-stage cardiac remodeling, and these patients are frequently denied surgery because they are

\footnotetext{
From the Departments of Thoracic and Cardiovascular Surgery ${ }^{\mathrm{a}}$ and Cardiovascular Medicine, ${ }^{\mathrm{c}}$ Heart and Vascular Institute, and the Department of Quantitative Health Sciences, ${ }^{\text {b }}$ Research Institute, Cleveland Clinic, Cleveland, Ohio.

This study was supported in part by the Kenneth Gee and Paula Shaw, $\mathrm{PhD}$, Chair in Heart Research, held by Dr Blackstone.

Disclosures: Dr Roselli is a consultant for Medtronic and Edwards Lifesciences and a teacher and speaker for Cook Medical and Terumo Medical. The other authors have nothing to disclose with regard to commercial support.

Read at the 38th Annual Meeting of The Western Thoracic Surgical Association, Maui, Hawaii, June 27-30, 2012.

Received for publication June 27, 2012; accepted for publication Aug 7, 2012; available ahead of print Sept 10, 2012.

Address for reprints: Eric E. Roselli, MD, Department of Thoracic and Cardiovascular Surgery, Cleveland Clinic, 9500 Euclid Ave/Desk J4-1, Cleveland, OH 44195-5108 (E-mail: roselle@ccf.org).

$0022-5223 / \$ 36.00$

Copyright (c) 2012 by The American Association for Thoracic Surgery

http://dx.doi.org/10.1016/j.jtcvs.2012.08.029
}

considered high risk. Results after aortic valve replacement (AVR) are conflicting, however, and have not validated the contention that PHT increases perioperative risk. ${ }^{5-8}$ In fact, most preoperative risk stratification models do not include the variable describing PHT because its impact on outcomes has not been consistently supported by previous analyses. ${ }^{9,10}$ In addition to the controversy surrounding the role of PHT in influencing early outcomes, few data are available on the natural history of PHT after AVR and on the relation of PHT to long-term survival.

In this study, we assess prevalence of PHT in a large cohort of patients undergoing AVR for severe AS, characterize their risk for PHT, assess postoperative PHT, and analyze its effect on early and late outcomes after AVR.

\section{PATIENTS AND METHODS \\ Patients}

From January 1996 to July 2010, a total of 4372 patients at Cleveland Clinic underwent primary AVR with or without coronary artery bypass grafting for severe AS (aortic valve area $<1 \mathrm{~cm}^{2}$ ) owing to degenerative or congenital (bicuspid) etiology. Only those receiving bovine pericardia valve prostheses were included, to control for confounding effects that device choice may play in outcomes. Patients with any of the following conditions were excluded from the study: endocarditis, rheumatic etiology, previous cardiac surgery, mitral or tricuspid valve procedure for 


\section{Abbreviations and Acronyms \\ $\mathrm{AS}=$ aortic stenosis \\ AVR $=$ aortic valve replacement \\ PHT = pulmonary hypertension \\ $\mathrm{RVSP}=$ right ventricular systolic pressure \\ TTE $=$ transthoracic echocardiogram}

indications other than functional/ischemic regurgitation, myectomy for hypertrophic obstructive cardiomyopathy, and concomitant aortic procedures (eg, aneurysm repair). Additional patient characteristics are listed in Table 1. Preoperative, operative, and postoperative variables were retrieved from the prospectively collected Cardiovascular Information Registry and the echocardiography database, both approved for use in research by the Cleveland Clinic Institutional Review Board, with patient consent waived.

\section{Pulmonary Hypertension}

Right ventricular systolic pressure (RVSP) was estimated echocardiographically and was used as the surrogate to assess PHT. Preoperative RVSP was available for 2385 patients; these patients constitute the study group. RVSP is calculated from the tricuspid valve peak velocity measured on preoperative transthoracic echocardiogram (TTE) using the equation $\left(\mathrm{RVSP}=10+4[\text { tricuspid valve peak velocity }]^{2}\right)$. Although RVSP was analyzed as a continuous variable, for descriptive purposes we created 3 groups from the distribution: RVSP less than $35 \mathrm{~mm} \mathrm{Hg}, 35$ to $50 \mathrm{~mm}$ $\mathrm{Hg}$, and greater than $50 \mathrm{~mm} \mathrm{Hg}$, corresponding to no PHT, moderate PHT, and severe PHT, respectively (see Table 1).

\section{End Points}

In-hospital outcomes. In-hospital outcomes and morbidity were defined as for the Society for Thoracic Surgeons National Adult Cardiac Database (see http://www.ctsnet.org/file/rptDataSpecifications252_1_ForVendorsPGS.pdf) and included return to the operating room for bleeding or tamponade, stroke, renal failure, new requirement for dialysis, prolonged ventilation, sepsis, and atrial fibrillation.

Postoperative PHT. Postoperative TTE reports were used to assess postoperative RVSP. Echocardiograms were performed routinely before discharge and at the discretion of referring physicians during follow-up. None of the echocardiographic data in this study are based on intraoperative studies. Follow-up echocardiograms were interpreted at as many time points as available for each patient.

A total of 3716 echocardiographic records on tricuspid valve regurgitation velocity were available for 1792 patients ( $75 \%$ of the total population). Number of patients and available TTEs at various times postoperatively are presented in Figure E1.

Survival. Active follow-up data at 2, 5, 10, and 15 years were obtained through the Cardiovascular Information Registry and supplemented with information from Social Security's Death Master File. ${ }^{11,12}$ A total of 10,218 patient-years of follow-up data were available for analysis. Mean follow-up time was $4.3 \pm 3.4$ years.

\section{Data Analysis}

Continuous variables are summarized as mean \pm standard deviation or as 15 th, 50th (median), and 85th percentiles when data are skewed. Simple comparisons were made using the Wilcoxon rank-sum nonparametric tests. Categorical data are summarized using frequencies and percentages. Comparisons were made using $\chi^{2}$ tests and Fisher's exact test where appropriate. All analyses were performed using SAS statistical software (version 9.2; SAS Institute, Inc, Cary, NC).
Time trend of RVSP. Time trend of RVSP was investigated by linear regression, with date of operation as the independent variable.

Correlates of preoperative RVSP. Multivariable linear regression was used to identify factors associated with preoperative RVSP. Variables considered in the analysis are listed in Appendix 1. Bagging was used for variable selection, ${ }^{13}$ with automated analysis of 1000 bootstrap samples. This was followed by tabulating the frequency of occurrence of single factors and closely related clusters of factors significant at $P<.05$. Factors appearing in $50 \%$ or more of analyses were retained in the final parsimonious model. Thereafter, this parsimonious model was augmented by non-statistically significant factors as indicated in Appendix 1 to transform it into a balancing score. ${ }^{14}$ This was used to adjust analyses of hospital outcomes.

Longitudinal trend of RVSP after AVR. To assess the temporal trend of mean RVSP after the procedure, we analyzed postoperative and follow-up TTEs longitudinally for change in mean RVSP. Nonlinear mixed-model regression was used to resolve a number of time phases to form a temporal decomposition model and to estimate shaping parameters of each phase. So that the repeated nature of the data (correlated within each patient) can be accommodated, each phase is independently modulated by a time function with an overall random intercept for all phases. Longitudinal regression for repeated continuous measurements was used to implement this temporal decomposition model.

Survival. Overall survival and stratified nonparametric survival estimates were obtained using the Kaplan-Meier method. A parametric method was used to resolve the number of phases of instantaneous risk of death (hazard function) and to estimate shaping parameters. ${ }^{15}$ Preoperative RVSP and the balancing score for RVSP on early and late mortality were forced into the models to evaluate the unadjusted effect of PHT.

\section{Presentation}

Because transformation of measurement scale was often necessary to meet statistical model assumptions, results are presented as regression coefficients and their standard errors. Uncertainty is also expressed by confidence limits or confidence intervals equivalent to \pm 1 standard error $(68 \%)$.

\section{RESULTS}

The majority of patients in the study had moderate to severe PHT $(\mathrm{n}=1774,74 \%)$. An investigation of trends in RVSP over time demonstrated no difference in prevalence of PHT over the 15-year span of this study. Median RVSP was $41 \mathrm{~mm} \mathrm{Hg}$; its cumulative distribution is shown in Figure 1.

Older female patients with higher body mass index and more severe AS, and those with left ventricular dysfunction, functional atrioventricular valve regurgitation, and more noncardiac comorbidities, had higher levels of RVSP preoperatively (Table 2).

Preoperative PHT was associated with worse postoperative outcomes (Table 3). Death, renal failure, and respiratory failure occurred more frequently in those with PHT. Patients with severe PHT also experienced longer intensive care unit and postoperative hospital stays than those without. Perioperative stroke, bleeding, sepsis, or atrial fibrillation did not occur statistically significantly more frequently in those with PHT. After RVSP as a continuous variable had been assessed and a multivariable balancing score had been created, the effect of RVSP on outcomes was less apparent 
TABLE 1. Preoperative and intraoperative patient characteristics

\begin{tabular}{|c|c|c|c|c|c|}
\hline \multirow[b]{2}{*}{ Characteristic } & \multirow[b]{2}{*}{$\begin{array}{c}\text { Overall } \\
(n=2385)\end{array}$} & \multicolumn{3}{|c|}{ Right ventricular systolic pressure } & \multirow[b]{2}{*}{$P$ valu } \\
\hline & & $\begin{array}{c}<35 \mathrm{~mm} \mathrm{Hg} \\
(\mathrm{n}=611)\end{array}$ & $\begin{array}{c}\text { 35-50 mm Hg } \\
(n=1199)\end{array}$ & $\begin{array}{c}>\mathbf{5 0} \mathbf{~ m m ~ H g} \\
(n=575)\end{array}$ & \\
\hline \multicolumn{6}{|l|}{ Patient } \\
\hline Age (y) & $74 \pm 10$ & $71 \pm 11$ & $74 \pm 9.6$ & $76 \pm 8.7$ & $<.0001$ \\
\hline Female & $1066(45)$ & $230(38)$ & $548(46)$ & $288(50)$ & $<.0001$ \\
\hline $\begin{array}{l}\text { Body mass index } \\
\left(\mathrm{kg} / \mathrm{m}^{2}\right)\end{array}$ & $28 \pm 6.3(\mathrm{n}=2358)$ & $28 \pm 5.4(\mathrm{n}=604)$ & $28 \pm 5.8(\mathrm{n}=1184)$ & $29 \pm 7.8(\mathrm{n}=570)$ & .08 \\
\hline Hypertension & $1802(76)$ & $422(69)$ & $909(76)$ & $471(82)$ & $<.0001$ \\
\hline $\begin{array}{l}\text { Coronary artery } \\
\text { disease* }\end{array}$ & $1280(57)(\mathrm{n}=2235)$ & $312(55)(\mathrm{n}=566)$ & $644(57)(\mathrm{n}=1126)$ & $324(60)(\mathrm{n}=543)$ & .3 \\
\hline $\begin{array}{l}\text { Prior myocardial } \\
\text { infarction }\end{array}$ & $432(18)$ & $83(14)$ & $216(18)$ & $133(23)$ & .0001 \\
\hline Prior PCI & $244(10)$ & $57(9.3)$ & $108(9.0)$ & $79(14)$ & .006 \\
\hline Preoperative AF/flutter & $260(12)(\mathrm{n}=2158)$ & $30(5.5)(\mathrm{n}=545)$ & $113(10)(\mathrm{n}=1085)$ & $117(22)(\mathrm{n}=528)$ & $<.0001$ \\
\hline COPD & $388(16)$ & $73(12)$ & $182(15)$ & $133(23)$ & $<.0001$ \\
\hline \multicolumn{6}{|l|}{ Valve-related } \\
\hline $\begin{array}{l}\text { Mean transvalvular } \\
\text { gradient }(\mathrm{mm} \mathrm{Hg})\end{array}$ & $48 \pm 16(n=2283)$ & $49 \pm 16(n=591)$ & $47 \pm 16(n=1142)$ & $48 \pm 17(\mathrm{n}=550)$ & .04 \\
\hline $\begin{array}{l}\text { Preoperative aortic } \\
\text { valve area }\left(\mathrm{cm}^{2}\right)\end{array}$ & $0.66 \pm 0.14(\mathrm{n}=2231)$ & $0.68 \pm 0.14(\mathrm{n}=585)$ & $0.67 \pm 0.13(n=1114)$ & $0.62 \pm 0.15(\mathrm{n}=532)$ & $<.0001$ \\
\hline Bicuspid aortic valve & $629(26)$ & $229(37)$ & $305(25)$ & $95(17)$ & $<.0001$ \\
\hline $\begin{array}{l}\text { Mitral regurgitation } \\
\text { grade }\end{array}$ & $(\mathrm{n}=2312)$ & $(\mathrm{n}=592)$ & $(\mathrm{n}=1159)$ & $(\mathrm{n}=561)$ & $<.0001$ \\
\hline 0 & $933(40)$ & $341(58)$ & $479(41)$ & $113(20)$ & \\
\hline $1+2+$ & $1192(52)$ & $237(40)$ & $617(53)$ & $338(60)$ & \\
\hline $3+4+$ & $187(8.0)$ & $14(2.4)$ & $63(5.4)$ & $110(20)$ & \\
\hline $\begin{array}{l}\text { Tricuspid regurgitation } \\
\text { grade }\end{array}$ & $(\mathrm{n}=2384)$ & $(\mathrm{n}=611)$ & $(\mathrm{n}=1198)$ & $(\mathrm{n}=575)$ & $<.0001$ \\
\hline 0 & $1117(47)$ & $448(73)$ & $564(47)$ & $105(18)$ & \\
\hline $1+/ 2+$ & $1107(46)$ & $159(26)$ & $597(50)$ & $351(61)$ & \\
\hline $3+4+$ & $160(7.0)$ & $4(0.65)$ & $37(3.1)$ & $119(21)$ & \\
\hline \multicolumn{6}{|l|}{ Echocardiographic } \\
\hline $\begin{array}{l}\text { Left ventricular } \\
\text { ejection fraction }(\%)\end{array}$ & $53 \pm 13(\mathrm{n}=2378)$ & $56 \pm 9.7(\mathrm{n}=610)$ & $54 \pm 12(\mathrm{n}=1196)$ & $47 \pm 16(\mathrm{n}=572)$ & $<.0001$ \\
\hline $\begin{array}{l}\text { Left ventricular mass } \\
\text { index }\end{array}$ & $129 \pm 41(\mathrm{n}=2234)$ & $124 \pm 38(\mathrm{n}=574)$ & $125 \pm 40(\mathrm{n}=1119)$ & $141 \pm 44(\mathrm{n}=541)$ & $<.0001$ \\
\hline $\begin{array}{l}\text { Left atrial volume } \\
\text { index } \dagger\end{array}$ & $23 \pm 13(\mathrm{n}=2117)$ & $19 \pm 9.4(\mathrm{n}=543)$ & $22 \pm 12(\mathrm{n}=1064)$ & $30 \pm 16(\mathrm{n}=510)$ & $<.0001$ \\
\hline \multicolumn{6}{|l|}{ Operative } \\
\hline CPB time (min) & $92 \pm 36$ & $87 \pm 35$ & $90 \pm 35$ & $100 \pm 39$ & $<.0001$ \\
\hline $\begin{array}{l}\text { Aortic clamp time } \\
\quad(\min )\end{array}$ & $73 \pm 30$ & $70 \pm 27$ & $72 \pm 30$ & $79 \pm 30$ & $<.0001$ \\
\hline $\begin{array}{l}\text { Prosthetic valve size } \\
\quad(\mathrm{mm})\end{array}$ & $22 \pm 2.1$ & $23 \pm 2.1$ & $22 \pm 2.1$ & $22 \pm 2.2$ & $<.0001$ \\
\hline \multicolumn{6}{|l|}{$\begin{array}{l}\text { Concomitant } \\
\text { procedures }\end{array}$} \\
\hline CABG & $1143(48)$ & $269(44)$ & $575(48)$ & $299(52)$ & .02 \\
\hline $\begin{array}{c}\text { Mitral valve } \\
\text { operation }\end{array}$ & $101(4.2)$ & $7(1.1)$ & $29(2.4)$ & $65(11)$ & $<.0001$ \\
\hline $\begin{array}{l}\text { Tricuspid valve } \\
\text { operation }\end{array}$ & $91(3.8)$ & $4(0.65)$ & $19(1.6)$ & $68(12)$ & $<.0001$ \\
\hline Ablation for $\mathrm{AF}$ & $215(9.0)$ & $33(5.4)$ & $97(8.1)$ & $85(15)$ & $<.0001$ \\
\hline Aorta repair & $121(5.1)$ & $26(4.3)$ & $61(5.1)$ & $34(5.9)$ & .4 \\
\hline
\end{tabular}

Values are reported as number and percentage or mean \pm standard deviation. $P C I$, Percutaneous coronary intervention; $C O P D$, chronic obstructive pulmonary disease; $C P B$, cardiopulmonary bypass; $C A B G$, coronary artery bypass grafting; $A F$, atrial fibrillation. * Stenosis $>50 \%$. $\dagger$ To body surface area. 


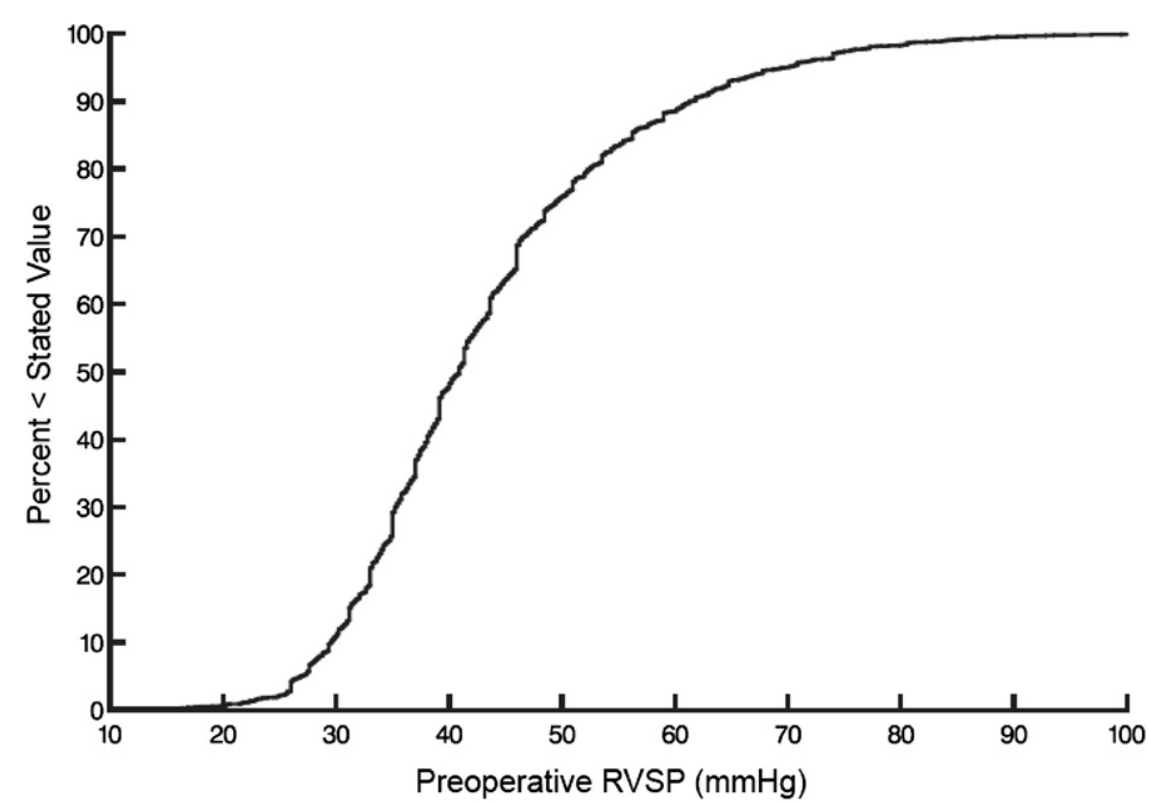

FIGURE 1. Cumulative distribution of pulmonary hypertension as assessed by right ventricular systolic pressure (RVSP).

(Table 4). In multivariable analysis, RVSP was independently associated only with return to the operating room for bleeding and prolonged postoperative length of stay (see Table 4).

Overall, compared with preoperative RVSP, average predischarge RVSP initially declined (Figure 2, A). This reduction was not maintained, however. Very early afterward,

TABLE 2. Correlates of preoperative right ventricular systolic pressure

\begin{tabular}{lccc}
\hline \multicolumn{1}{c}{ Variable } & Estimate \pm SE & $\boldsymbol{P}$ value & $\begin{array}{c}\text { Reliability } \\
(\%)^{*}\end{array}$ \\
\hline Demography & & & \\
Age & $6.93 \pm 1.57$ & $<.0001$ & 91 \\
Female & $1.52 \pm 0.478$ & .002 & 63 \\
BMI & $1.60 \pm 0.397$ & $<.0001$ & 85 \\
NYHA class & $1.35 \pm 0.574$ & .02 & 73 \\
Cardiac comorbidity & & & \\
LV dysfunction & $-6.67 \pm 0.945$ & $<.0001$ & 98 \\
AV peak gradient & $6.39 \pm 0.681$ & $<.0001$ & 99 \\
Preoperative LA volume index $\dagger$ & $0.111 \pm 0.018$ & $<.0001$ & 55 \\
Tricuspid regurgitation severity & $5.19 \pm 0.263$ & $<.0001$ & 97 \\
Mitral regurgitation severity & $0.67 \pm 0.273$ & .01 & 89 \\
Concomitant mitral valve repair & $3.19 \pm 1.20$ & .008 & 62 \\
Noncardiac comorbidity & & & \\
COPD & $1.85 \pm 0.590$ & .002 & 83 \\
Preoperative dialysis & $4.67 \pm 1.96$ & .02 & 80 \\
Pharmacologically treated & $1.19 \pm 0.544$ & .03 & 67 \\
$\quad$ diabetes & & & \\
Bilirubin & $1.69 \pm 0.534$ & .002 & 85 \\
Intercept & $-25.29 \pm 7.74$ & .001 & - \\
\hline SE, Standard error; $B M I$, body mass index; $N Y H A$, New York Heart Association; $L V$ \\
left ventricular; $A V$, aortic valve; $L A$, left atrial; $C O P D$, chronic obstructive pulmonary \\
disease. *Percent of times factor appeared in 1000 bootstrap models. $\dagger$ To body sur- \\
face area.
\end{tabular}

RVSP increased and plateaued. In those with preoperative PHT (moderate and and high PHT), RVSP rose again after about $3 \frac{1}{2} 2$ years. In those without preoperative PHT, the latephase rise in pressure was not observed during follow-up (Figure 2, B).

Overall unadjusted estimated survival at 6 months and 1 , 2,5 , and 10 years was $93 \%, 91 \%, 88 \%, 75 \%$, and $46 \%$, respectively. The hazard function resolved to 3 phases: an early phase up to 6 months, a constant phase, and then a late phase after 5 years. Survival was lower in patients with higher RVSP $(P<.0001)$ : Unadjusted survival at 1 , 5 , and 10 years, respectively, was $96 \%, 85 \%$, and $63 \%$ for RVSP less than $35 \mathrm{~mm} \mathrm{Hg} ; 92 \%, 77 \%$, and $45 \%$ for

TABLE 3. Hospital outcomes stratified by right ventricular systolic pressure

\begin{tabular}{|c|c|c|c|c|}
\hline \multirow[b]{3}{*}{ Outcome } & \multicolumn{3}{|c|}{ Right ventricular systolic pressure } & \multirow{3}{*}{$\begin{array}{c}P \\
\text { value }\end{array}$} \\
\hline & $\begin{array}{c}<35 \mathrm{~mm} \mathrm{Hg} \\
(\mathrm{n}=611)\end{array}$ & $\begin{array}{c}\text { 35-50 mm Hg } \\
(n=1199)\end{array}$ & $\begin{array}{c}>50 \mathrm{~mm} \mathrm{Hg} \\
(\mathrm{n}=\mathbf{5 7 5})\end{array}$ & \\
\hline & No. $(\%)$ & No. $(\%)$ & No. $(\%)$ & \\
\hline Hospital death & $6(0.98)$ & $23(1.9)$ & $18(3.1)$ & .03 \\
\hline Bleeding & $20(3.3)$ & $46(3.8)$ & $31(5.4)$ & .15 \\
\hline Stroke & $7(1.1)$ & $21(1.8)$ & $14(2.4)$ & .2 \\
\hline Renal failure & $23(3.8)$ & $69(5.8)$ & $68(12)$ & $<.0001$ \\
\hline $\begin{array}{l}\text { Renal failure } \\
\text { requiring dialysis }\end{array}$ & $5(0.82)$ & $18(1.5)$ & $22(3.8)$ & .0003 \\
\hline Prolonged ventilation & $22(4.9)$ & $91(10)$ & $81(19)$ & $<.0001$ \\
\hline Sepsis & $5(0.82)$ & $27(2.3)$ & $19(3.3)$ & .01 \\
\hline Atrial fibrillation & $194(32)$ & $424(35)$ & $188(33)$ & .3 \\
\hline ICU stay $(\mathrm{h})^{*}$ & $23 / 27 / 72$ & $23 / 28 / 94$ & $24 / 49 / 144$ & $<.0001$ \\
\hline $\begin{array}{l}\text { Postoperative stay } \\
\text { (d)* }\end{array}$ & $5.2 / 6.4 / 13$ & $5.3 / 7.6 / 15$ & $6.3 / 11 / 23$ & $<.0001$ \\
\hline
\end{tabular}


TABLE 4. Effect of right ventricular systolic pressure (continuous measure) before and after balancing score adjustment

\begin{tabular}{lcccc}
\hline \multicolumn{1}{c}{ Outcome } & $\begin{array}{c}\text { Unadjusted } \\
\text { estimate } \pm \mathbf{S E}\end{array}$ & $\begin{array}{c}\boldsymbol{P} \\
\text { value }\end{array}$ & $\begin{array}{c}\text { Adjusted } \\
\text { estimate } \pm \text { SE }\end{array}$ & $\begin{array}{c}\boldsymbol{P} \\
\text { value }\end{array}$ \\
\hline Hospital death & $0.029 \pm 0.0093$ & .002 & $0.0020 \pm 0.012$ & .9 \\
Bleeding & $0.0186 \pm 0.0071$ & .008 & $0.020 \pm 0.0086$ & .02 \\
Renal failure & $0.026 \pm 0.0054$ & $<.0001$ & $0.0061 \pm 0.0067$ & .4 \\
Prolonged & $0.035 \pm 0.0052$ & $<.0001$ & $0.0073 \pm 0.0063$ & .2 \\
$\quad$ ventilation & & & & \\
Sepsis & $0.016 \pm 0.0097$ & .09 & $0.00074 \pm 0.012$ & $>.9$ \\
ICU stay (h)* & $1.45 \pm 0.19$ & $<.0001$ & $0.24 \pm 0.22$ & .3 \\
Postoperative & $0.11 \pm 0.0108$ & $<.0001$ & $0.027 \pm 0.012$ & .03 \\
$\quad$ & & & & \\
stay (d)* & & & & \\
Hospital stay (d)* & $0.16 \pm 0.013$ & $<.0001$ & $0.021 \pm 0.015$ & .17 \\
\hline SE Standard error; ICU intensive care unit $*$ Linear regression. &
\end{tabular}

RVSP of 35 to $50 \mathrm{~mm} \mathrm{Hg}$; and $85 \%, 62 \%$, and $31 \%$ for RVSP greater than $50 \mathrm{~mm} \mathrm{Hg}$ (Figure 3). As is clear from Figure 3, RVSP level stratifies patients predominantly within the first year after AVR. This is corroborated by the balancing-score-adjusted analysis, which demonstrated an increase in early risk (coefficient, $0.013 \pm 0.0059$; $P=.02$; a hazard ratio of 1.14 per $10 \mathrm{~mm} \mathrm{Hg}$, or a $14 \%$ increased risk) but probably not of late risk (coefficient, $0.0052 \pm 0.0036 ; P=.15$; a hazard ratio of 1.053 per 10 $\mathrm{mm} \mathrm{Hg}$, or a $5.3 \%$ increased risk). Five-year predicted survival according to preoperative RVSP is shown in Figure 4.

\section{DISCUSSION}

\section{Principal Findings}

Our analysis confirms that PHT is common (74\%) in patients undergoing primary AVR for severe AS. The strongest risk factors for PHT are older age, obesity, more advanced aortic valve disease and ventricular dysfunction, associated atrioventricular valve disease, and comorbid pulmonary, respiratory, and liver disease. PHT is associated with worse perioperative outcomes. After AVR, it initially declines but then progresses in patients who had it preoperatively and is associated with decreased late survival.

\section{Prevalence and Risk Factors}

Prevalence of PHT in patients with severe AS ranged from $29 \%$ to $74 \%$ in this study. Variability is in part due to inconsistent definitions of PHT. ${ }^{16}$ We used TTEassessed RVSP as a continuous variable to identify the relationship between PHT and outcomes. Others have used a combination of right heart catheterization assessments or echocardiograms. In previous studies, patients have been artificially separated into groups on the basis of these measurements. Although RVSP is a calculated value, use of echocardiography allowed for a consistent measure that we could follow over time. With complete echocardiographic data available for more than $75 \%$ of our patients, the current study is the largest of its kind to date.
PHT is complex and can be attributable to multiple causes, classified as arterial PHT, PHT secondary to heart disease, PHT secondary to hypoxic lung disease, PHT secondary to thromboembolic disease, or miscellaneous. ${ }^{17} \mathrm{Al}-$ though this study lacks the detail to differentiate various causes, most patients in this large cohort have PHT from cardiac causes or a combination of cardiac and other causes, an entity that is poorly understood. ${ }^{18}$ Current guidelines for treating AS generally recommend delaying surgery until patients with severe AS begin having symptoms or objective findings consistent with development of late-phase cardiac remodeling (ie, left ventricular dysfunction or a positive result from a stress test). Given the current state of practice, it is not surprising that PHT is so prevalent or that its risk factors include higher transvalvular gradients, left ventricular dysfunction, increased left atrial diameter, older age, and severe dysfunction of other major organ systems.

\section{PHT and Early Outcomes}

There is little question that patients with severely symptomatic AS do better with AVR than without, and this has been confirmed in patients with severe PHT as well. ${ }^{4,6}$ Understanding the effect of PHT on surgical risk, however, has been challenged by inadequately powered studies and lack of PHT variables in larger databases. Melby and colleagues ${ }^{8}$ demonstrated a significant difference in perioperative mortality among patients with $(9.7 \%)$ and without (5.4\%) PHT, but multivariable analysis did not show PHT to independently predict worse outcome. Similarly, overall mortality and several other complications were worse in patients with higher RVSP in our study. In multivariable analysis, however, the effect of RVSP was not as strong. PHT does not develop in isolation. Its etiology is multifactorial, and associated comorbid conditions may contribute to surgical risk. By the time severe PHT develops in patients with severe AS, they may be at increased surgical risk for many reasons.

Transcatheter AVR therapies may provide a less-invasive option for patients with late-stage disease and have been shown to be superior to medical management for inoperable candidates. Transcatheter AVR has not been shown to be superior to surgical AVR, however, in eligible high-risk patients. In a Canadian multicenter analysis of transcatheter AVR, PHT was predictive of both 30-day (odds ratio, 2.09) and late (hazard ratio, 1.88) mortality. ${ }^{19}$ Because durability of transcatheter AVR devices is less well understood than that of standard surgical valves, understanding the role PHT plays in prognosis may prove important during the preoperative selection process.

\section{PHT After AVR}

Prior studies have demonstrated reduced pulmonary pressures after AVR ${ }^{5,8}$ Roithinger and colleagues ${ }^{20}$ showed that the drop in pulmonary pressures was greater in those receiving larger valves. Melby and colleagues ${ }^{8}$ showed that 

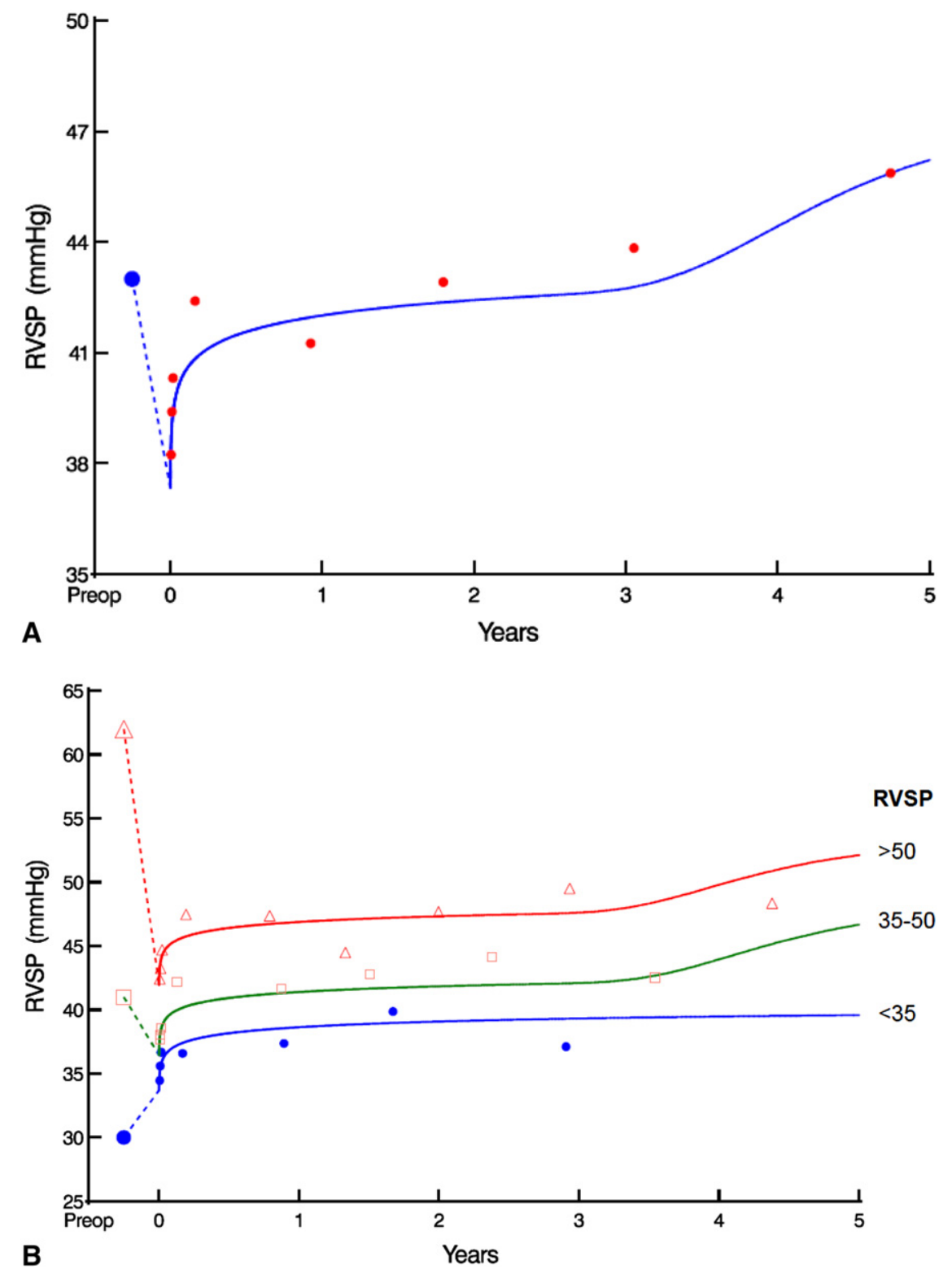

FIGURE 2. Trends in right ventricular systolic pressure $(R V S P)$ after aortic valve replacement. Symbols represent data grouped within time frames, without regard for repeated assessment, simply to provide crude verification of model fit. Larger symbols depict preoperative mean values. preop, Preoperative. A, Entire cohort. B, Stratified by preoperative RVSP.

pulmonary pressures remained lower than preoperative values at a mean follow-up of more than 3 years, but echocardiographic data were available for only $28 \%$ of survivors. Although we demonstrated an initial drop in RVSP similar to that found in other studies, this reduction was not maintained. During follow-up, 2 increasing phases of pressure rise were seen: 1 early after surgery and the other at about $3 \frac{1}{2}$ years postoperatively. When stratified by preoperative RVSP, patients without PHT did not experience the late increase (see Figure 2, $B$ ).

It has been suggested that diastolic dysfunction is a major determinant of PHT in patients with $\mathrm{AS}^{2}$
This study demonstrated persistent increases in PHT over time, especially when the process has already begun. Again, this indicates that many of these patients are possibly being treated too late in the disease process.

\section{PHT and Late Outcomes}

$\mathrm{We}^{21}$ have previously demonstrated that presence of severe left ventricular hypertrophy is associated with decreased survival after AVR in a similar cohort of patients. This effect was magnified by severity of AS and small prosthesis size. These findings suggest that relying on symptoms 


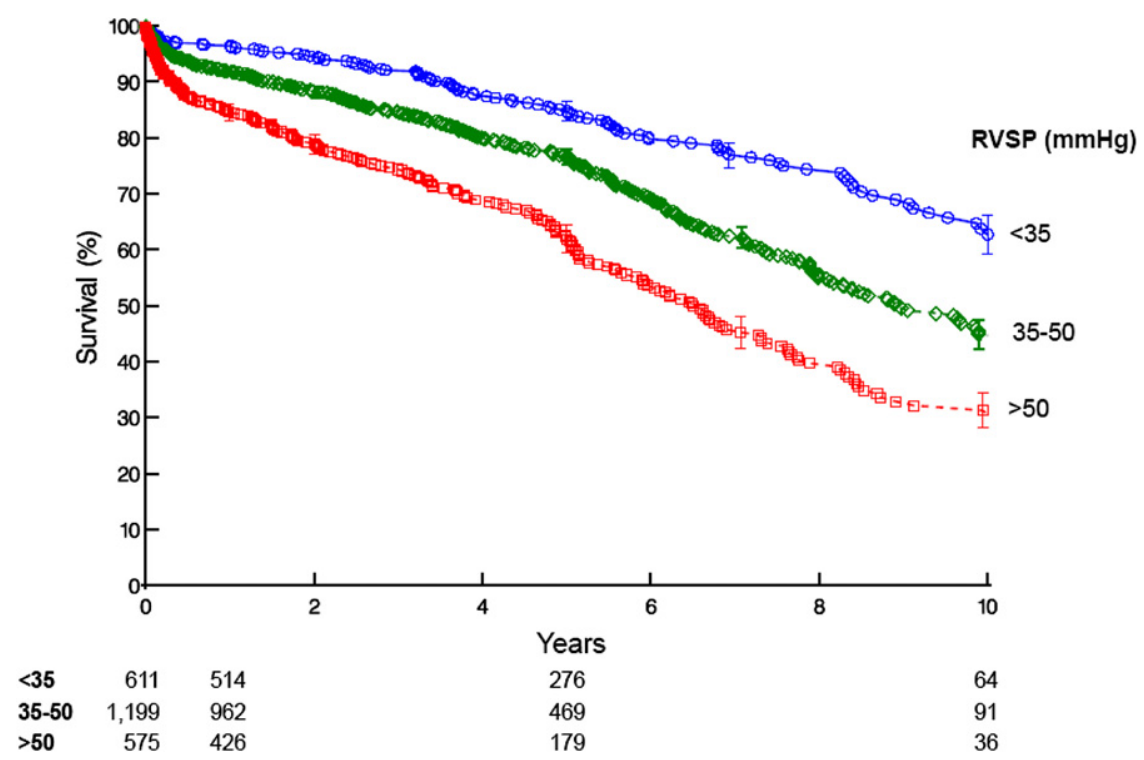

FIGURE 3. Survival after aortic valve replacement stratified by preoperative right ventricular systolic pressure (RVSP). Each symbol represents a death, vertical bars are $68 \%$ confidence limits representing \pm 1 standard error, and numbers below horizontal axis are patients remaining at risk.

as an indication is inadequate and that AVR should be performed before irreversible myocardial changes occur. Similarly, we have demonstrated in this study that severity of preoperative PHT, another indication of late myocardial remodeling, is associated with worse late outcomes after AVR.

\section{Clinical Implications}

Although RVSP may decrease soon after AVR, once PHT has developed in patients with severe AS the process may not be reversible and may explain why late outcomes are worse in those with higher RVSP. Understanding a patient's long-term prognosis is an important factor in the decisionmaking process before AVR and pertains not only to indications for proceeding but also to approach and prosthesis selection. It is important to consider the severity of irreversible changes manifest as PHT when evaluating patients for aortic valve intervention. Lack of PHT regression and evidence of its progression, as well as reduced long-term survival, in patients who have undergone AVR suggest that earlier intervention for AS should be studied more closely.

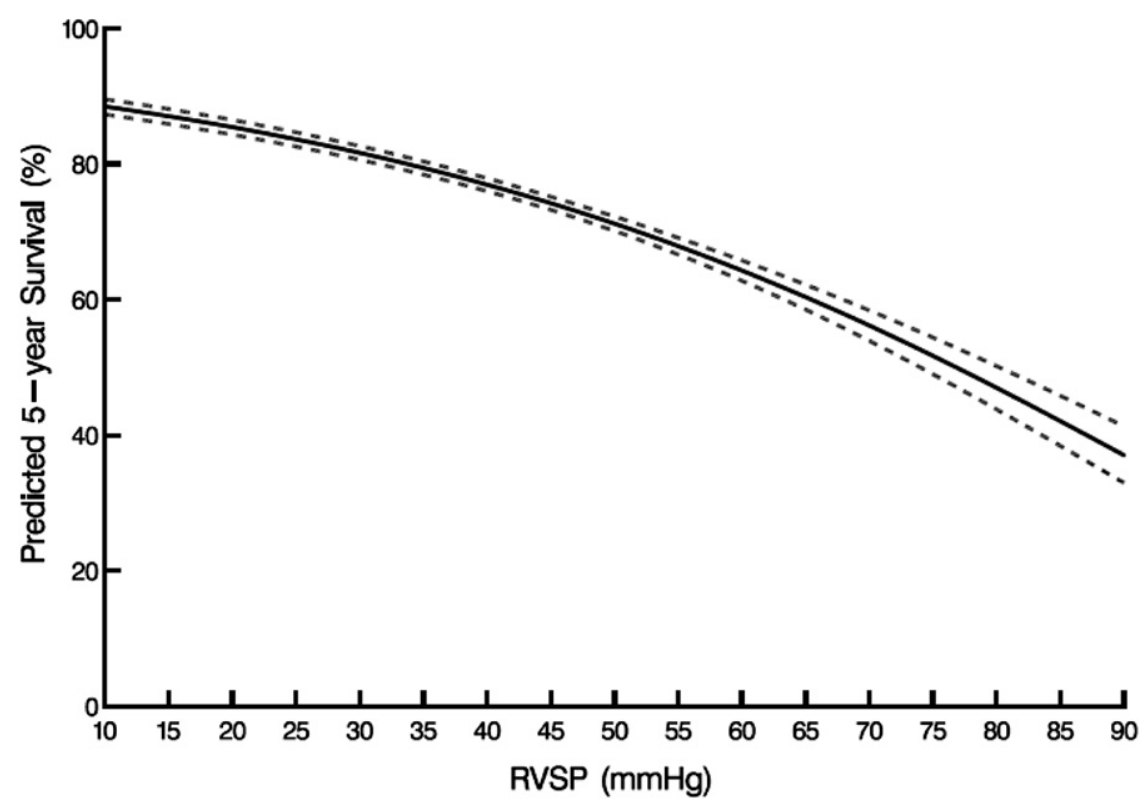

FIGURE 4. Predicted 5-year survival after aortic valve replacement as assessed by right ventricular systolic pressure (RVSP). Solid line is parametric estimate enclosed within dashed $68 \%$ confidence limits representing \pm 1 standard error. 


\section{References}

1. Silver K, Aurigemma G, Krendel S, Barry N, Ockene I, Alpert J. Pulmonary artery hypertension in severe aortic stenosis: incidence and mechanism. Am Heart J. 1993;125:146-50.

2. Faggiano P, Antonini-Canterin F, Ribichini F, D'Aloia A, Ferrero V, Cervesato E, et al. Pulmonary artery hypertension in adult patients with symptomatic valvular aortic stenosis. Am J Cardiol. 2000;85:204-8.

3. Johnson LW, Hapanowicz MB, Buonanno C, Bowser MA, Marvasti MA, Parker FB Jr. Pulmonary hypertension in isolated aortic stenosis: hemodynamic correlations and follow-up. J Thorac Cardiovasc Surg. 1988;95:603-7.

4. Malouf JF, Enriquez-Sarano M, Pellikka PA, Oh JK, Bailey KR, Chandrasekaran K, et al. Severe pulmonary hypertension in patients with severe aortic valve stenosis: clinical profile and prognostic implications. J Am Coll Cardiol. 2002;40:789-95.

5. Tracy GP, Proctor MS, Hizny CS. Reversibility of pulmonary artery hypertension in aortic stenosis after aortic valve replacement. Ann Thorac Surg. 1990;50: 89-93

6. Pai RG, Varadarajan P, Kapoor N, Bansal RC. Aortic valve replacement improves survival in severe aortic stenosis associated with severe pulmonary hypertension. Ann Thorac Surg. 2007;84:80-5.

7. Aragam JR, Folland ED, Lapsley D, Sharma S, Khuri SF, Sharma GV. Cause and impact of pulmonary hypertension in isolated aortic stenosis on operative mortality for aortic valve replacement in men. Am J Cardiol. 1992;69:1365-7.

8. Melby SJ, Moon MR, Lindman BR, Bailey MS, Hill LL, Damiano RJ Jr. Impact of pulmonary hypertension on outcomes after aortic valve replacement for aortic valve stenosis. J Thorac Cardiovasc Surg. 2011;141:1424-30.

9. Nilsson J, Algotsson L, Hoglund P, Luhrs C, Brandt J. Comparison of 19 preoperative risk stratification models in open-heart surgery. Eur Heart J. 2006; 27:867-74.

10. Brown JM, O'Brien SM, Wu C, Sikora JA, Griffith BP, Gammie JS. Isolated aortic valve replacement in North America comprising 108,687 patients in 10 years: changes in risks, valve types, and outcomes in the Society of Thoracic Surgeons National Database. J Thorac Cardiovasc Surg. 2009;137:82-90.
11. Boyle CA, Decoufle P. National sources of vital status information: extent of coverage and possible selectivity in reporting. Am J Epidemiol. 1990;131:160-8.

12. Newman TB, Brown AN. Use of commercial record linkage software and vital statistics to identify patient deaths. J Am Med Inform Assoc. 1997;4:233-7.

13. Breiman L. Bagging predictors. Machine Learning. 1996;24:123-40.

14. Rosenbaum PR, Rubin DB. The central role of the propensity score in observational studies for causal effects. Biometrika. 1983;70:41-55.

15. Blackstone EH, Naftel DC, Turner ME Jr. The decomposition of time-varying hazard into phases, each incorporating a separate stream of concomitant information. J Am Stat Assoc. 1986;81:615-24.

16. Denault A, Deschamps A, Tardif JC, Lambert J, Perrault L. Pulmonary hypertension in cardiac surgery. Curr Cardiol Rev. 2010;6:1-14

17. Simonneau G, Galie N, Rubin LJ, Langleben D, Seeger W, Domenighetti G, et al. Clinical classification of pulmonary hypertension. J Am Coll Cardiol. 2004;43: 5S-12S.

18. McLaughlin VV, Archer SL, Badesch DB, Barst RJ, Farber HW, Lindner JR, et al. ACCF/AHA 2009 expert consensus document on pulmonary hypertension: a report of the American College of Cardiology Foundation Task Force on Expert Consensus Documents and the American Heart Association developed in collaboration with the American College of Chest Physicians; American Thoracic Society, Inc; and the Pulmonary Hypertension Association. J Am Coll Cardiol. 2009;53:1573-619.

19. Rodes-Cabau J, Webb JG, Cheung A, Ye J, Dumont E, Feindel CM, et al. Transcatheter aortic valve implantation for the treatment of severe symptomatic aortic stenosis in patients at very high or prohibitive surgical risk: acute and late outcomes of the multicenter Canadian experience. J Am Coll Cardiol. 2010;55: 1080-90.

20. Roithinger FX, Krennmair G, Deutsch M, Pachinger O. The influence of aortic valve prosthesis diameter on the reversibility of pulmonary hypertension in isolated aortic stenosis. J Heart Valve Dis. 1994;3:185-9; discussion 90.

21. Mihaljevic T, Nowicki ER, Rajeswaran J, Blackstone EH, Lagazzi L, Thomas J, et al. Survival after valve replacement for aortic stenosis: implications for decision making. J Thorac Cardiovasc Surg. 2008;135:1270-8; discussion 8-9. 


\section{APPENDIX 1. VARIABLES CONSIDERED IN MULTIVARIABLE ANALYSES*}

\section{Demography}

Age (years), ${ }^{*}$ gender,* height $(\mathrm{cm})$, weight $(\mathrm{kg})$, body surface area $\left(\mathrm{m}^{2}\right)$, body mass index $\left(\mathrm{kg} / \mathrm{m}^{2}\right)^{*}$

\section{Preoperative Status}

New York Heart Association functional class (I-IV),* Canadian Angina Class (I-IV), emergency surgery, syncope, dyspnea on exertion, shortness of breath, paroxysmal nocturnal dyspnea, ${ }^{*}$ orthopnea*

\section{Ventricular Dysfunction}

Left ventricular dysfunction grade $(1=$ none, $2=$ mild, $3=$ moderate, $4=$ moderately severe, $5=$ severe), ${ }^{*}$ prior myocardial infarction

\section{Aortic Valve}

Pathology: Regurgitation, stenosis

Function/size: Orifice area $\left(\mathrm{cm}^{2}\right)$, mean gradient $(\mathrm{mm} \mathrm{Hg})$, peak gradient $(\mathrm{mm} \mathrm{Hg})^{*}$

Etiology: Degenerative

\section{Other Valve Pathology}

Tricuspid regurgitation, mitral regurgitation*

\section{Cardiac Comorbidity}

Preoperative atrial fibrillation*; number of coronary systems with more than $50 \%$ stenosis*; stenosis of the left anterior descending coronary artery, left main trunk, right coronary artery, left circumflex coronary artery $(>50 \%$, any); family history of coronary artery disease; ventricular arrhythmia; complete heart block*; history of endocarditis; heart failure*

\section{Noncardiac Comorbidity}

Treated diabetes,* hypertension,* stroke,* peripheral arterial disease, chronic obstructive pulmonary disease,* renal failure, blood urea nitrogen $(\mathrm{mg} / \mathrm{dL}),{ }^{*}$ creatinine $(\mathrm{mg} / \mathrm{dL})$, ${ }^{*}$ bilirubin $(\mathrm{mg} / \mathrm{dL})$, ${ }^{*}$ cholesterol (total, highdensity lipoprotein, low-density lipoprotein, [mg/dL], triglycerides $(\mathrm{mg} / \mathrm{dL})$, hematocrit $(\%)^{*}$

\section{Left Atrium}

Diameter $(\mathrm{cm})$, volume $\left(\mathrm{cm}^{3}\right)$, volume index*

\section{Left Ventricle}

Morphology: Inner diameter in diastole $(\mathrm{cm})$, inner diameter in systole $(\mathrm{cm})$, diastolic volume $(\mathrm{mL})$, systolic volume $(\mathrm{mL})$, diastolic volume index $\left(\mathrm{mL} / \mathrm{m}^{2}\right)$, systolic volume index $\left(\mathrm{mL} / \mathrm{m}^{2}\right)$, dilated left ventricle

Function: Fractional shortening, ejection fraction $(\%),{ }^{*}$ relative wall thickness (wall stress)

Mass: Mass (g), mass index $\left(\mathrm{g} / \mathrm{m}^{2}\right)$, posterior wall thickness $(\mathrm{cm}),{ }^{*}$ septal thickness $(\mathrm{cm})$

\section{Details of AVR}

Valve size, in vitro effective orifice area, ratio: valve area/ body surface area, ratio: effective orifice area/body surface area, internal valve area, efficiency: effective orifice area/ internal valve area

\section{Concomitant Procedure}

Coronary artery bypass grafting, ${ }^{*}$ mitral valve repair* or replacement, tricuspid valve repair, atrial fibrillation, septal myectomy

\section{Experience}

Date of operation*

*Variables included in RVSP balancing score. 


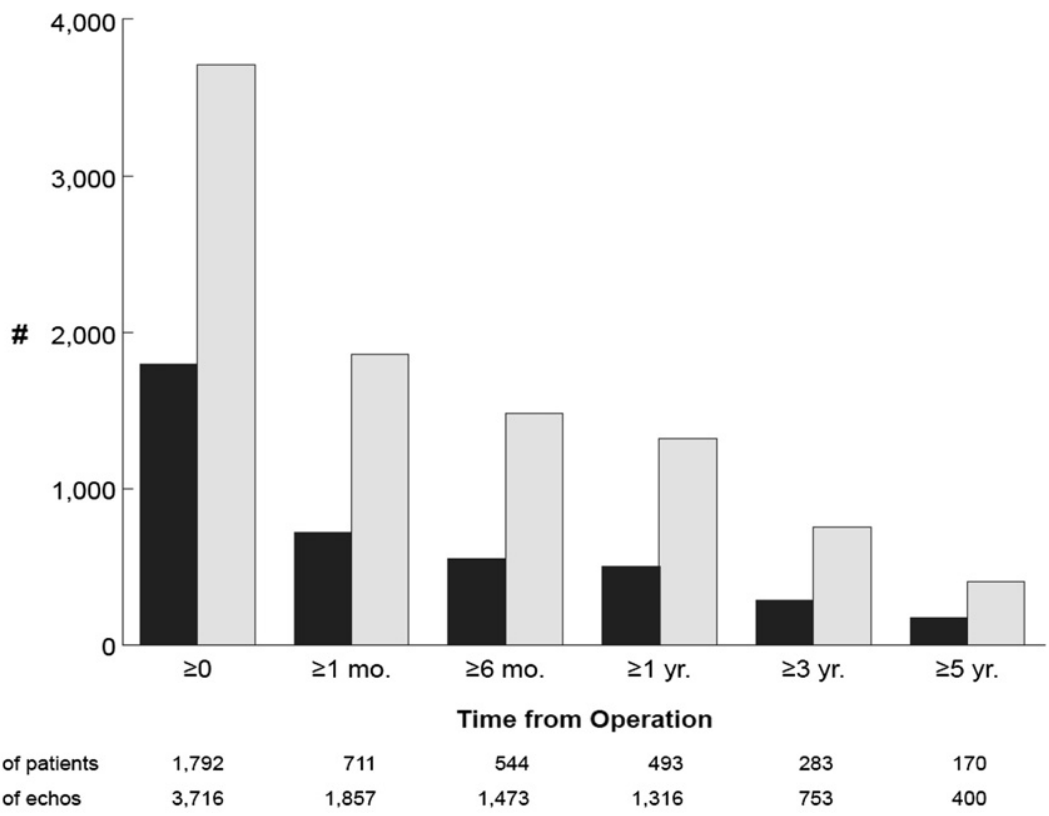

FIGURE E1. Number of patients with echocardiograms available at and beyond various time points, and number of echocardiograms available for analysis. 